\title{
Sensory Profiling of Two Commercial Ground-Roasted Arabica Filter Coffees Presented with and without Sweetener and Milk
}

\author{
Chloe N. Stokes, Joseph P. Kerry*, Maurice G. O’Sullivan* \\ The Food Packaging Group, School of Food and Nutritional Sciences, University College Cork, Cork, Ireland \\ Email: ^maurice.osullivan@ucc.ie, *joe.kerry@ucc.ie
}

How to cite this paper: Stokes, C.N., Kerry, J.P. and O'Sullivan, M.G. (2018) Sensory Profiling of Two Commercial Ground-Roasted Arabica Filter Coffees Presented with and without Sweetener and Milk. Food and Nutrition Sciences, 9, 1408-1423.

https://doi.org/10.4236/fns.2018.912102

Received: August 31, 2018

Accepted: December 25, 2018

Published: December 28, 2018

Copyright $\odot 2018$ by authors and Scientific Research Publishing Inc. This work is licensed under the Creative Commons Attribution International License (CC BY 4.0).

http://creativecommons.org/licenses/by/4.0/

\begin{abstract}
The aim of this study was to evaluate the descriptive sensory attributes of coffee presented to trained assessors in four different ways (black unsweetened, black sweetened, white unsweetened and white sweetened), and also to obtain information on untrained assessor hedonic preferences for the same four different presentation styles. Sensory profiles of two commercial ground-roasted Arabica coffees (currently available on the Irish and UK marketplace) were studied through Sensory Acceptance Testing $(n=24)$ and Ranking Descriptive Analysis $(n=20)$. ANOVA-Partial Least Square Regression (APLSR) was used to analyse the experimental data. This study established that the naïve assessors preferred both coffee samples when served white unsweetened and white sweetened. In terms of the descriptive attributes, it is evident that when coffee is served black, the attributes are more pronounced.
\end{abstract}

\section{Keywords}

Sensory Profiles, Coffees, Attributes

\section{Practical Application}

The results of this study will provide researchers with information on how they should present samples in development studies. It will also provide information to coffee companies and people interested in the area of marketing and coffee as it provides information on assessor coffee habits and preferences and an insight into how various coffee attributes are affected by adding sweetener and/milk to 
coffee.

\section{Introduction}

Coffee is one of the world's most popular beverages, owing to its distinctive aroma and flavour. Coffee is grown worldwide in more than 50 countries. The majority of these countries are developing countries [1]. World coffee consumption is growing each year. The global consumption of coffee has shown an average increase of $2.5 \%$ per year since 2011 [2]. Even with coffee consumption increasing each year there is little information available about assessor coffee choice and preference in terms of coffee consumption habits. Coffee drinkers have different coffee consuming and taste preference and like to imbibe coffee in different ways (i.e. black, with milk/creamer, sweetened etc.). For example, it is common practice to add creamer to a coffee beverage in the United States, and in Brazil assessors generally add whole milk, skimmed milk or semi-skimmed milk to their coffee beverage prior to consumption [3]. A survey conducted by the Irish Coffee Council and Amárach Research [4] on 1000 Irish assessors reported that three quarters of Irish adults drink coffee and that $87 \%$ of coffee drinkers added something to their beverage, with $70 \%$ of 15 - 24 year olds adding milk and $47 \%$ of 15 - 24 year olds adding sugar and $8 \%$ adding cream. Thus, assessors have developed a hedonic preference for how they like their coffee. In this present study, by presenting coffee in four different presentation styles (black unsweetened, black sweetened, white unsweetened and white sweetened) and asking assessors to rank the coffees against one another it allows the complete descriptive nature of the coffee to be explored.

Generally, assessors add milk/creamers to coffee beverages to increase the body of the coffee and to reduce sourness, bitterness and astringency of the coffee beverage [5]. Previous studies have also reported that gender has a large influence on coffee presentation style [6] [7]. Narian et al. 2004 [7], evaluated assessor coffee drinking preference $(n=150)$ and examined segmentation. They also evaluated the coffee samples presented black unsweetened, white unsweetened and white sweetened using a trained panel $(n=13)$ but results were focused on how it affected the coffee blends.

To our knowledge, no study has evaluated how coffee presented, standardised, in four different ways (black unsweetened, black sweetened, white unsweetened and white sweetened) affects the descriptive sensory attributes of the beverages when ranking the four presentation styles amongst each other. Additionally, consumers who use milk and sugar in their hot beverages dose to their own personal tastes and thus this poses a dilemma for sample presentation and standardisation of sensory experiments. A standardised product presented black, with or without sugar or milk will likely be a departure from the assessor's ideal way of consuming the product. Traditionally, the preferred solution was to present samples black for all, but again this is a departure for many from their regular consumption format. The presented study also looks at which presenta- 
tion style untrained assessors $(n=24)$ prefer when comparing the standardised (black unsweetened, black sweetened, white unsweetened and white sweetened) products presented to them. Thus, the aim of this present study was to investigate how assessors perceived the sensory (hedonic, descriptive) properties of two different commercial black coffees when presented black unsweetened, black sweetened, white unsweetened and white sweetened in order to obtain a greater understanding of coffee beverage composition on resulting sensory profiles.

\section{Materials and Methods}

\subsection{Coffee Samples}

Two different commercial ground-roasted coffees were selected for this trial. From previous trials carried out on a vast range of coffees available in the Republic of Ireland, the ground-roasted filter coffees that panellists' preferred was established, consequently these were the coffee products that were used in this study [8] [9] [10]. Both coffees were made from ground roasted 100\% arabica beans and had a Total Dissolved Solids reading of $0.86 \%$ and $0.81 \%$. Coffee samples were bought from an Irish supermarket. Samples were stored at room temperature, in a cool, dry storage area until the trial commenced. All coffees were opened fresh on each trial day. The sweetener used in this trial was white sugar sachets (Brand: GEM) which were purchased from a local supermarket and stored in a cool dry place until the trial started. The whitener used in this trial was CMP fresh milk which was purchased from a local supermarket on the day of the trial and was stored in the fridge $\left(2^{\circ} \mathrm{C}-5^{\circ} \mathrm{C}\right)$.

\subsection{Sample Preparation}

Each coffee was prepared following the preparation protocol to ensure coffee samples were standardised throughout the trial.

The standardised preparation protocol for ground-roasted filter coffee (Cafetière):

A kettle was filled with water and boiled to $100^{\circ} \mathrm{C}$. The National Coffee Association [11] recommends the water for brewing should be in the range of $90.6^{\circ} \mathrm{C}$ $96.1^{\circ} \mathrm{C}$, thus once the temperature of the water in the kettle decreased to $95^{\circ} \mathrm{C}$ $\left( \pm 1^{\circ} \mathrm{C}\right)$ the cafetière was warmed by filling it with approx. $130 \mathrm{~mL}$ of the boiled water and swirling the water around for $10 \mathrm{~s}$ prior to disposing of the water. Fresh ground-roasted coffee (12.5 g) was then placed into the warmed cafetière, as International standards suggest a ratio of $5-9 \mathrm{~g}$ coffee per $100 \mathrm{~mL}$ of water [12]. The cafetière was filled with approx. $250 \mathrm{~mL}$ of the boiled water and the contents were stirred using a metal tablespoon. After a three min extraction period the cafetière plunger was pressed down on contents and $177 \mathrm{~mL}$ of the brewed coffee was poured into a $237 \mathrm{~mL}$ paper-based cups (methyl cellulose internally and externally coated with polyethylene). Milk and/or sugar were added to the samples accordingly. $15 \mathrm{~mL}$ of fresh milk (CMP dairy, Cork, Ireland) was added to the required samples to whiten. One sugar sachet (5 g) was added to 
the required coffee samples to sweeten them. Condiments were added by the researchers carrying out the trial. Once the contents of the cup were at $70^{\circ} \mathrm{C}$ $\left( \pm 1^{\circ} \mathrm{C}\right)$ they were served to assessors. From a previous study carried out by the team $70.8^{\circ} \mathrm{C}$ was found to be the preferred temperature for serving black coffee thus this is why we chose to use this temperature in this study [8].

\subsection{Percentage Total Dissolved Solids (\% TDS)}

Three readings were taken from three different samples and an average was calculated from the three samples. The method used was as follows:

An ice bath was prepared. The Refractometer (VST Inc. digital refractometer from SCAE store, Essex, UK) was calibrated using distilled water. A kettle was used to boil water to $100^{\circ} \mathrm{C}$ and a thermometer (model: testo 110. Tolerable margin of error $\pm 1^{\circ} \mathrm{C}$. Supplied by Testo AG, Germany) was used to monitor the temperature after boiling and once the temperature of the water reached $95^{\circ} \mathrm{C}$ $\left( \pm 1^{\circ} \mathrm{C}\right)$ the coffee was prepared following the Standardised protocol for filtered brewed coffee preparation in this paper. A plastic $10 \mathrm{~mL}$ syringe (BD Plastipak syringe) was used to transfer $10 \mathrm{~mL}$ of the brewed coffee from the paper-based cup into a ceramic cup and the ceramic cup was immediately placed on the ice bath. The temperature of the coffee in the ceramic cup was continuously monitored until it reached $22^{\circ} \mathrm{C}\left( \pm 2^{\circ} \mathrm{C}\right)$. For filter coffee, a $10 \mathrm{~mL}$ syringe (BD Luer-Lok Tip $10 \mathrm{~mL}$ syringe) was used to take up $4 \mathrm{~mL}$ of the coffee. A syringe filter was then placed on the syringe and $2 \mathrm{~mL}$ of the contents of the syringe was transferred to a clean ceramic cup. Using a $1 \mathrm{~mL}$ plastic pipette dropper $0.3 \mathrm{~mL}$ of the filter coffee sample was transferred into the sample well of the refractometer. The sample cover was closed and the sample was left for $20 \mathrm{~s}$ in the sample well to equilibrate to the temperature of the instrument. Then the \% TDS was obtained and recorded. A new filter and syringe was used for each measurement.

\subsection{Sensory Acceptance Testing}

Sensory acceptance testing was conducted using untrained assessors [13] [14] ( $n=$ $24)$ in the age range of $18-52$. They consisted of 10 males and 14 females, were chosen on the basis that they regularly consumed coffee. In terms of occupation, three of the males were in professional jobs, five were postgraduate students and two were undergraduate students. Two of the males drank black coffee, one drank white coffee, four drank white coffee with sweetener and three drank black coffee with sweetener. Out of the females two were in professional jobs, six were post -graduate students and six were undergraduate students. Two of the females drank black coffee, several drank white coffee, three drank white coffee with sweetener and two drank black coffee with sweetener.

Sensory analysis sessions were conducted in University College Cork's sensory evaluation laboratory which conformed to international standards [14], under white light. For the Sensory Acceptance Testing, untrained assessors $(n=24)$ evaluated the samples for liking of aroma, liking of flavour and overall accept- 
ability. Assessors marked their degree of liking for each sample on a $10-\mathrm{cm}$-line scale ranging from 0 (extremely dislike) at the left to 10 (extremely like) at the right and rating subsequently scored in $\mathrm{cm}$ from the left. For both the Sensory Acceptance and Ranking Descriptive Analysis of the presentation of samples were identical. One coffee was evaluated per session, in which the coffee was presented in the four different presentation methods, simultaneously. Assessors were presented with a black unsweetened coffee, a black sweetened coffee, a white unsweetened coffee and a white sweetened coffee, simultaneously, and asked to rank the samples against each other. The four samples were identical in appearance. A three-digit random code was present on the outside of each of the cups for identification. Each sample consisted of approx. $177 \mathrm{~mL}$ filter coffee in $237 \mathrm{~mL}$ light brown, single-walled, paper-based cups (methyl cellulose internally and externally coated with polyethylene) and was served at $70^{\circ} \mathrm{C}$. A thermal imaging camera (SATIR Hotfind L-T) was used was used to confirm the temperature of each sample prior to analysis. Samples were presented in a random order in a balanced block design to prevent first order and carry-over effects [15]. Each assessor evaluated each sample in duplicate [16] over a total of four sessions, in which four samples were evaluated simultaneously during each session, with one session conducted per day to prevent fatigue occurring in assessors. Sessions were carried out from $9.30 \mathrm{am}-1.00 \mathrm{pm}$ and took approx. 30 - $50 \mathrm{~min}$.

\subsection{Ranking Descriptive Assessors (RDA)}

Ranking Descriptive Analysis [17] was undertaken using trained panellists in the age range of $21-52$ and consisted of 11 males and 13 females. They were also chosen on the basis that they regularly consumed filter coffee. In terms of occupation, two of the males were in professional jobs, eight were postgraduate students and one was an undergraduate student. Out of the females one was in a professional job and several were postgraduate students and five were undergraduate students. Each of the assessors $(n=20)$ had previously taken part in coffee studies conducted by the team and had training experience in black coffee sensory evaluation. Assessors also took part in determining the sensory terminology of coffee and a sensory term reduction process. A total of 10 attributes were ultimately chosen to profile the products to be tested and which reflected the main sensory variation in samples (Table 1). Trained assessors used descriptive analysis to evaluate the descriptive attributes present in Table 1. Each assessor was asked to rank the intensity of the sample on a $10-\mathrm{cm}$-line scale ranging from 0 (non-extreme) at the left to 10 (extreme) at the right and rating subsequently scored in $\mathrm{cm}$ from left. Samples were presented in a random order in a balanced block design to prevent first order and carry-over effects [15]. Each assessor evaluated each sample in duplicate [16] over a total of four sessions, in which four samples were evaluated simultaneously during each session, with one session conducted per day to prevent fatigue occurring in assessors. Sessions were carried out from $9.30 \mathrm{am}-1.00 \mathrm{pm}$ and took approx. $30-50 \mathrm{~min}$. 
Table 1. Attributes evaluated (ICO, 2010, [59]).

\begin{tabular}{|c|c|}
\hline Attribute & Definition \\
\hline Liking aroma & How likable is the aroma \\
\hline Liking flavour & How likable is the flavour \\
\hline Overall acceptability & Overall acceptance of the sample \\
\hline Smokey/burnt aroma & The smell associated with smoke from burning wood \\
\hline Coffee aroma & The unique smell associated with coffee products \\
\hline Coffee flavour & Overall intensity of coffee flavour \\
\hline Roasted/burnt flavour & The flavour descriptor similar to that found in burnt food \\
\hline Earthy flavour & $\begin{array}{l}\text { Reminiscent of raw potato flavour and the odour associated } \\
\text { with fresh earth, wet soil or hummus. Undesirable in coffee }\end{array}$ \\
\hline Fruity flavour & Reminiscent of fruit flavour \\
\hline Sweet taste & $\begin{array}{l}\text { Fundamental taste sensation of which sucrose is typical. } \\
\text { Generally associated with sweet aroma descriptors } \\
\text { such as fruity, chocolate and caramel. }\end{array}$ \\
\hline Bitter taste & $\begin{array}{l}\text { A primary taste characterized by a solution of caffeine, } \\
\text { quinine and certain alkaloids. The taste is considered } \\
\text { desirable up to a certain level and is affected by the } \\
\text { degree of roast brewing procedures. }\end{array}$ \\
\hline Astringent aftertaste & $\begin{array}{l}\text { Characteristic of an after-taste sensation consistent of a } \\
\text { drying effect in the mouth. Undesirable in coffee. }\end{array}$ \\
\hline Full body & $\begin{array}{l}\text { Describes the physical properties of the coffee. Full body would } \\
\text { describe a strong full mouth-feel as opposed to being thin }\end{array}$ \\
\hline
\end{tabular}

\section{Data Analysis}

ANOVA-Partial Least Square Regression (APLSR) was used to analyse the raw data generated from this study using Unscrambler software version 10.3 (Camo, Norway). The X-matrix was designed as $0 / 1$ variables for coffee samples and the Y-matrix sensory variables. To achieve significant results the regressions coefficient were analysed by Jack-knifing, which is based on cross-validation and stability plots [18]. Table 3 and Table 4 display corresponding $P$-values of the regression coefficients. A map of the hedonic and descriptive sensory attributes was plotted using ANOVA-Partial Least Squares Regression (APLSR) Analysis.

\section{Results and Discussion}

SAT is a hedonic sensory technique used extensively for the various food and beverage [19]-[28] products. Figure 1 shows the APLSR plot for the SAT data for the two commercial coffees assessed by the naïve assessors in this study and Table 2 indicates the sample codes visible on the APLSR plot. From Figure 1 and Table 3 it is evident that the presentation of the coffee (black unsweetened, black sweetened, white unsweetened and white sweetened) effects the assessor's overall sensory experience. For both of the commercial coffee samples evaluated in this study similar results were obtained. 
Table 2. Codes present on the PLS plot and the ANOVA value Table.

\begin{tabular}{cc}
\hline Code & Description \\
\hline 1B & Coffee 1 served black \\
2B & Coffee 2 served black \\
1BS & Coffee 1 served black with sweetener \\
2BS & Coffee 2 served black with sweetener \\
1W & Coffee 1 served white \\
2W & Coffee 2 served white \\
1WS & Coffee 1 served white with sweetener \\
2WS & Coffee 2 served white with sweetener \\
\hline
\end{tabular}

Table 3. ANOVA values for regression coefficients from APLSR for the hedonic sensory data.

\begin{tabular}{cccc}
\hline & Liking aroma & Liking flavour & Overall acceptability \\
\hline 1B & $-0.001^{* * *}$ & $-0.827 \mathrm{~ns}$ & $-0.116 \mathrm{~ns}$ \\
2B & $-0.007^{* *}$ & $-0.005^{* *}$ & $-0.000^{* * *}$ \\
1BS & $-0.000^{* * *}$ & $-0.000^{* * *}$ & $-0.001^{* * *}$ \\
2BS & $-0.000^{* * *}$ & $-0.010^{* *}$ & $-0.000^{* * *}$ \\
1W & $0.000^{* * *}$ & $0.000^{* * *}$ & $0.000^{* * *}$ \\
2W & $0.004^{* *}$ & $0.000^{* * *}$ & $0.066 \mathrm{~ns}$ \\
1WS & $0.000^{* * *}$ & $0.000^{* * *}$ & $0.000^{* * *}$ \\
2WS & $0.000^{* *}$ & $0.926 \mathrm{~ns}$ & $0.000^{* * *}$ \\
\hline
\end{tabular}

$\mathrm{P}$-values are from the estimated regression coefficients from anova-partial least squares regression (aplsr). The sign dictates whether the correlation is positive or negative. Significance of regression coefficients: $\mathrm{ns}=$ not significant, ${ }^{\star}=P<0.05,{ }^{* *}=P<0.01,{ }^{* *}=P<0.001$.

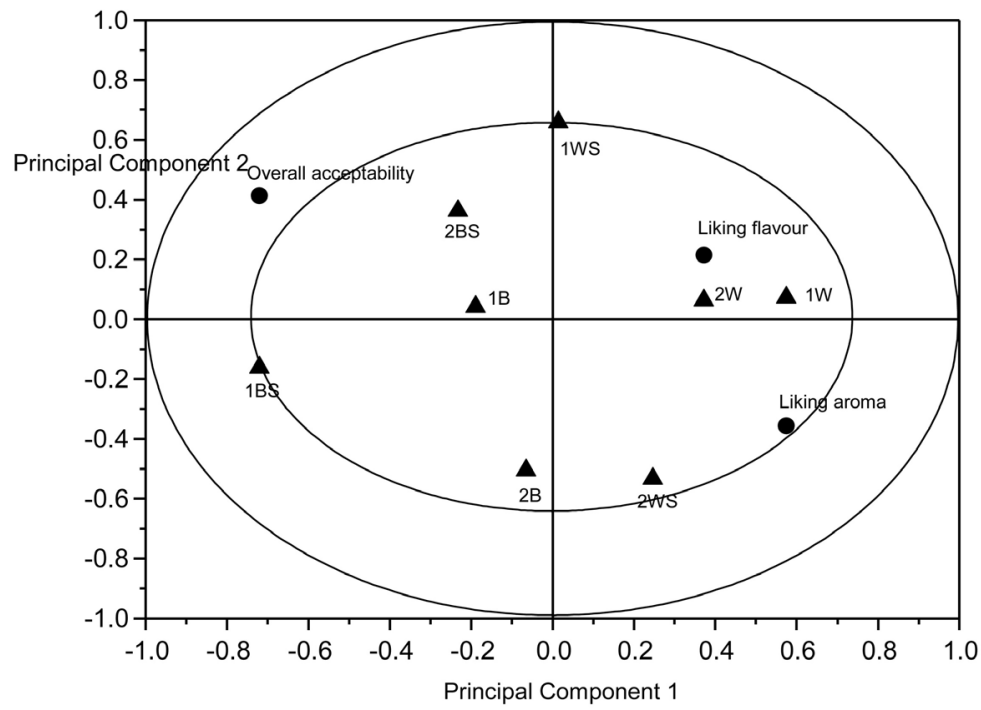

Figure 1. ANOVA-Partial Least Squares Regression (APLSR) correlation loadings plot for the sensory hedonic evaluation for the two coffee samples. Shown are the loadings of the $\mathrm{x}$ - and $\mathrm{y}$-variables for the first $4 \mathrm{pcs}$ for $\bullet=$ individual treatments, $\boldsymbol{\Delta}=$ sensory descriptor. PC 1 vs. PC 2 presented. 
Results accumulated from the naive assessors showed that the least preferred samples, for both commercial coffees, was when they were served black unsweetened and black sweetened. Coffees served in this manner were negatively significantly $(P<0.010)$ correlated to liking of aroma. Samples 2B, 1BS, 2BS were negatively significantly $(P<0.010)$ correlated to liking of flavour and overall acceptability. Sample 1B was negatively correlated to liking of flavour and overall acceptability, although not significantly.

In contrast, for both coffee samples evaluated, the assessors preferred the coffees when they were served white unsweetened and white sweetened. From Figure 1, in the upper right-hand quadrant of the plot it is evident that samples 1WS, $1 \mathrm{~W}$ and $2 \mathrm{~W}$ were positively correlated to overall acceptability and liking of flavour. Thus samples $1 \mathrm{~W}, 2 \mathrm{~W}, 1 \mathrm{WS}$ and $2 \mathrm{WS}$ were positively correlated to each of the hedonic attributes, with $1 \mathrm{~W}, 1 \mathrm{WS}$ and $2 \mathrm{WS}$ being positively significantly $(P<0.001)$ correlated to liking of aroma and overall acceptability. Sample $2 \mathrm{~W}$ was also positively significantly $(P<0.010)$ correlated to liking of aroma. Samples $1 \mathrm{~W}, 2 \mathrm{~W}$ and $1 \mathrm{WS}$ were positively significantly $(P<0.001)$ correlated to liking of flavour.

From the short questionnaire the assessors filled out prior to commencing the trial, it is evident that a total of four of the assessors drink black unsweetened coffee and five of the assessors drink black sweetened coffee in their normal lifestyle, thus this may account for the preference toward white unsweetened and white sweetened coffees in this study. A study with a larger naïve panel could be conducted in future work to strengthen these findings.

RDA is a method extensively used for the descriptive evaluation of various food and beverage [29]-[55] products. Figure 2 shows the APLSR plot for the RDA data for the two commercial coffees assessed in this study and Table 2 indicates the sample codes visible on the APLSR plot. From Figure 2 and Table 4 it is evident that the presentation of the coffee (black unsweetened, black sweetened, white unsweetened and white sweetened) affected the sensory profile of the coffee. Assessors found the black unsweetened coffee positively correlated to each of the descriptive attributes (with the exception of sweet taste and full body). In contrast, assessors found the black sweetened, white unsweetened and white sweetened coffee negatively correlated to the attributes (with the exception of sweet taste and full body).

From Figure 2, in the lower right-hand quadrant it is evident that sample 1B and $2 \mathrm{~B}$ were positively correlated to earthy flavour. In the upper right-hand quadrant of the plot it is evident that sample $2 \mathrm{~B}$ was positively correlated to earthy flavour, coffee flavour, coffee aroma, fruity flavour, smokey/burnt aroma, bitter taste and astringent aftertaste. From Table 4, it is clear that sample 2B is positively significantly $(P<0.001)$ correlated to smokey/burnt aroma, coffee aroma, coffee flavour, roasted/burnt flavour, earthy flavour, fruity flavour, bitter taste and astringent aftertaste. Similarly, sample 1B is positively significantly $(P<$ 0.001 ) correlated to smokey/burnt aroma, coffee aroma, coffee flavour, earthy 


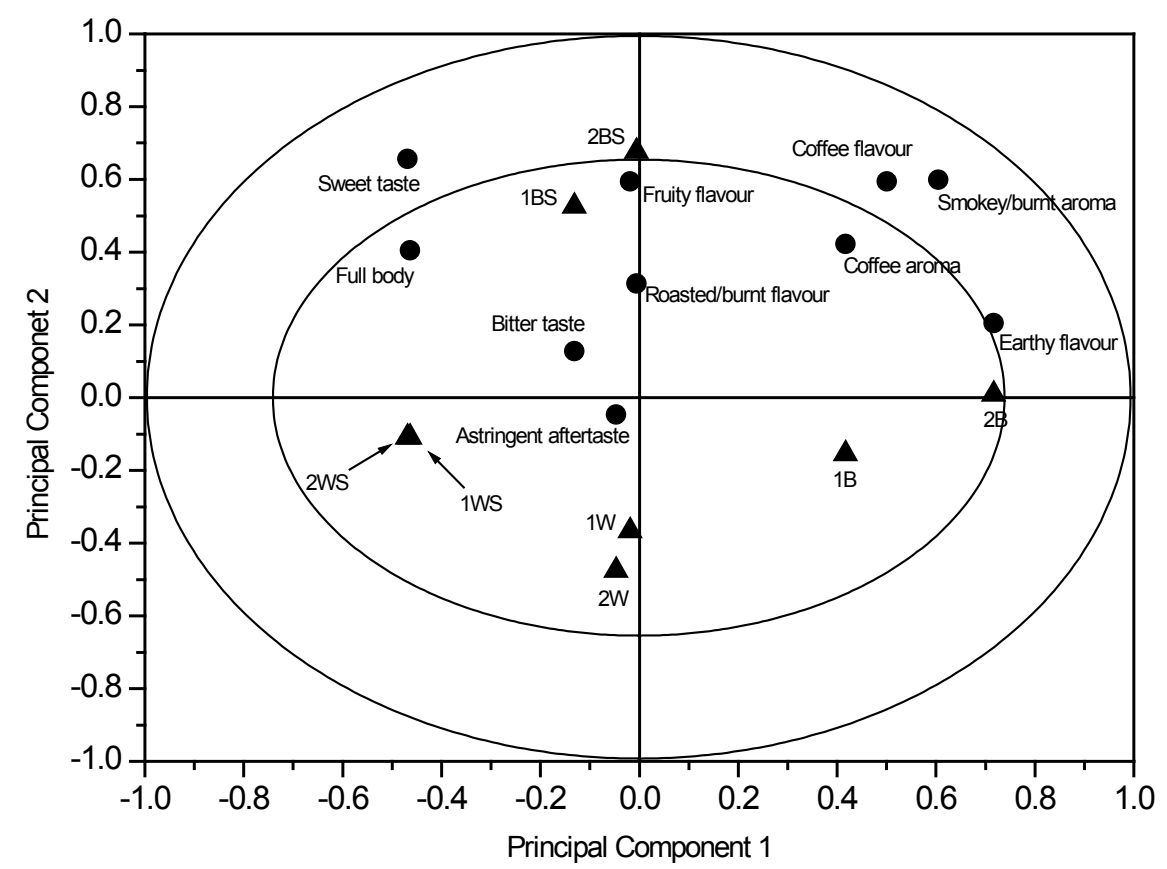

Figure 2. ANOVA-Partial Least Squares Regression (APLSR) correlation loadings plot for the sensory descriptive evaluation for the two coffee samples. Shown are the loadings of the $\mathrm{x}$ - and $\mathrm{y}$-variables for the first $4 \mathrm{pcs}$ for $\boldsymbol{\Delta}$ = individual treatments, $\bullet=$ sensory descriptor PC 1 vs. PC 2 presented.

Table 4. ANOVA values for regression coefficients from APLSR for the descriptive sensory data.

\begin{tabular}{|c|c|c|c|c|c|c|c|c|c|c|}
\hline & $\begin{array}{l}\text { Smokey/burnt } \\
\text { aroma }\end{array}$ & $\begin{array}{l}\text { Coffee } \\
\text { aroma }\end{array}$ & $\begin{array}{l}\text { Coffee } \\
\text { flavour }\end{array}$ & $\begin{array}{l}\text { Roasted/burnt } \\
\text { flavour }\end{array}$ & Sweet taste & $\begin{array}{l}\text { Earthy } \\
\text { flavour }\end{array}$ & $\begin{array}{l}\text { Fruity } \\
\text { flavour }\end{array}$ & Bitter taste & $\begin{array}{l}\text { Astringent } \\
\text { aftertaste }\end{array}$ & Full body \\
\hline $1 \mathrm{~B}$ & $0.000^{* * *}$ & $0.000^{* * *}$ & $0.001^{\star * \star}$ & $0.166 \mathrm{~ns}$ & $-0.000^{* * *}$ & $0.000^{* * *}$ & $0.000^{* * *}$ & $0.686 \mathrm{~ns}$ & $0.241 \mathrm{~ns}$ & $-0.000^{* * *}$ \\
\hline $2 \mathrm{~B}$ & $0.000^{* * *}$ & $0.000^{* * *}$ & $0.000^{* * *}$ & $0.000^{\star * *}$ & $-0.000^{* * *}$ & $0.000^{* * *}$ & $0.000^{* * *}$ & $0.000^{* * *}$ & $0.000^{* * *}$ & $-0.000^{\star * *}$ \\
\hline 1BS & $-0.015^{\star *}$ & $-0.320 \mathrm{~ns}$ & $-0.658 \mathrm{~ns}$ & $-0.001^{* * *}$ & $0.000^{* * *}$ & $-0.000^{\star * \star}$ & $-0.000^{* * *}$ & $-0.000^{* * *}$ & $-0.000^{* * *}$ & $0.000^{* * *}$ \\
\hline 2BS & $-0.000^{* * *}$ & $-0.000^{* * *}$ & $-0.004^{\star *}$ & $-0.000^{* * *}$ & $0.000^{* * *}$ & $-0.000^{\star * *}$ & $-0.000^{* * *}$ & $-0.000^{* * *}$ & $-0.000^{* * *}$ & $0.000^{\star * *}$ \\
\hline $1 \mathrm{~W}$ & $-0.000^{* * *}$ & $-0.380 \mathrm{~ns}$ & $-0.000^{\star * \star}$ & $-0.000^{\star * *}$ & $0.000^{* * *}$ & $-0.000^{\star * *}$ & $-0.022^{\star}$ & $-0.000^{\star * *}$ & $-0.000^{* * *}$ & $0.000^{* * *}$ \\
\hline $2 \mathrm{~W}$ & $-0.000^{\star * *}$ & $-0.644 \mathrm{~ns}$ & $-0.000^{* * *}$ & $-0.000^{* * *}$ & $0.000^{* * *}$ & $-0.001^{\star * *}$ & $-0.000^{* * *}$ & $-0.000^{* * *}$ & $-0.000^{* * *}$ & $0.000^{* * *}$ \\
\hline 1WS & $-0.000^{\star * *}$ & $-0.000^{\star \star *}$ & $-0.000^{* * *}$ & $-0.000^{* * *}$ & $0.000^{* * *}$ & $-0.000^{\star * \star}$ & $-0.000^{* * *}$ & $-0.000^{\star * \star}$ & $-0.000^{\star * \star}$ & $0.000^{\star * *}$ \\
\hline $2 \mathrm{WS}$ & $-0.000^{* * *}$ & $-0.000^{* * *}$ & $-0.000^{* * *}$ & $-0.000^{* * *}$ & $0.000^{* * *}$ & $-0.000^{* * *}$ & $-0.000^{* * *}$ & $-0.000^{* * *}$ & $-0.000^{* * *}$ & $0.000^{* * *}$ \\
\hline
\end{tabular}

P-values are from the estimated regression coefficients from anova-partial least squares regression (aplsr). The sign dictates whether the correlation is positive or negative. Significance of regression coefficients: NS $=$ Not Significant, ${ }^{*}=P<0.05,{ }^{* *}=P<0.01,{ }^{* *}=P<0.001$.

flavour and fruity flavour. Both samples $1 \mathrm{~B}$ and $2 \mathrm{~B}$ were negatively significantly $(P<0.001)$ correlated sweet taste and full body.

From Table 4 it can be seen that samples $2 \mathrm{BS}, 1 \mathrm{WS}$ and $2 \mathrm{WS}$ are negatively significantly $(P<0.010)$ correlated to smokey/burnt aroma, coffee aroma, coffee flavour, roasted/burnt flavour, earthy flavour, fruity flavour, bitter taste and astringent aftertaste. In contrast, they were positively significantly $(P<0.001)$ correlated to sweet taste and full body.

From Figure 2, in the upper left-hand quadrant of the plot it is evident that sample $1 \mathrm{BS}$ is positively correlated to sweet taste and full body. In Table 4, 1BS 
is positively significantly $(P<0.001)$ correlated to these two attributes. It can also be seen that sample 1BS is negatively significantly $(P<0.010)$ correlated to smokey/burnt aroma, roasted/burnt flavour, earthy flavour, fruity flavour, bitter taste and astringent aftertaste.

From Table 4, it is clear that samples $1 \mathrm{~W}$ and $2 \mathrm{~W}$ are negatively significantly $(P<0.050)$ correlated to smokey/burnt aroma, coffee flavour, roasted/burnt flavour, earthy flavour, fruity flavour, bitter taste and astringent aftertaste. In contrast, they were positively significantly $(P<0.001)$ correlated to sweet taste and full body. Chiralertpong et al. 2008 [56] reported that sweeteners reduced the roasted and coffee-like notes in coffee beverage and the current results would support these findings.

The results from this present study support results reported by Narian et al. 2003 [57], that a decrease in the intensity of specific attributes occurs during whitening of coffee. As in this present study, the coffees served white (1W and $2 \mathrm{~W}$ ) were negatively correlated to the majority of the descriptive attributes and in contrast, the samples served black ( $1 \mathrm{~B}$ and $2 \mathrm{~B}$ ) were positively correlated to the majority of the descriptive attributes assessed.

Narain et al. 2004 [7], carried out a sensory study in which they evaluated assessor preference $(n=150)$ in various filter coffee blends and examined segmentation. The assessors evaluated twelve different filter coffee samples, over two sessions, as they normally would consume coffee (with/without milk and sugar) and ranked them on a five-point scale. Results indicated that gender had a large influence on coffee presentation style as it was reported that sweetener reduced the hedonic scores in the female assessors and milk increased the preference scores for males. This study was more focused on gaining information on assessor drinking preferences and looking at the difference between commercial coffees available than the presentation styles, as the assessors evaluated each of the coffees how they normally would make coffee. In our study, assessors evaluated two commercial coffees for all four of the presentation styles (black unsweetened, black sweetened, white unsweetened and white sweetened) by ranking the samples against each other. Unfortunately, due to our small panel size $(n=24)$ we couldn't segment the results into gender preferences. Cristovam et al. 2000, [6] noted that males and females had different preferences for espressos and espresso-milk coffees. This is an area that deserves future study using both instant and filtered coffee types. Cristovam et al. 2000 [6] also noted that milk changed the panellist's preference for coffee type, which we can conclude from our present study is true, as the exact same coffee sample was presented in four different presentation styles and white unsweetened coffee and white sweetened coffee was preferred by the naïve panel $(n=24)$ in this present study.

Narain et al. 2004 [7], also used a trained panel $(n=13)$ to profile the 12 commercial filter coffees when presented black unsweetened, white unsweetened and white sweetened; however, their results were focused on how each of the individual presentations of the coffee affected 12 different coffees evaluated. In contrast, our study evaluated how four presentation methods compared against 
each other for two commercial coffee samples using RDA.

Lundgren et al. 1978, [58] reported that the ability of assessors to assess the degree of liking of sucrose levels in coffee beverages is independent of behavioural responses. It is important to note that for our sensory acceptance testing half of the assessors $(n=12)$ drank coffee without sweetener and the other half of the assessors $(n=12)$ drank coffee with sweetener.

Chiralertpong et al. 2008 [56], evaluated the effect of added creamer and sweetener on espresso coffee samples. They found that coffee-like and roasted notes were reduced by the presence of sweeteners. Our white sweetened coffee sample demonstrated similar results, however our black sweetened coffee samples demonstrated contradicting results.

\section{Conclusion}

Coffee drinkers have developed a hedonic preference for how they like to imbibe coffee (black, with milk, sweetened etc.). In the present study, by presenting coffee in the different ways (black unsweetened, black sweetened, white unsweetened and white sweetened) allowed us to determine which presentation style untrained assessors prefer $(n=24)$ and also how trained assessors $(n=20)$ perceived the descriptive attributes associated with the different coffee beverages. From this study, it is clear that sweetening and whitening filter coffee has a large influence on how coffee attributes are perceived by assessors. Results showed that when the coffee was served black, the assessors found the descriptive attributes to be more pronounced. In terms of preference, the naïve assessors preferred both coffee samples when they were served white unsweetened and white sweetened.

\section{Acknowledgements}

The research reported in this manuscript was part funded by Enterprize Ireland through the innovation partnership scheme with industrial support offered and supplied by Bewley's LTD. Bewley's Limited, Northern Cross, Malahide Road, Dublin 17, Ireland.

\section{Conflicts of Interest}

The authors declare no conflicts of interest regarding the publication of this paper.

\section{References}

[1] Van der Stegen, G.H.D. (2003) Enhancement of Coffee Quality by Mould Prevention. Food Control, 14, 245-249. https://doi.org/10.1016/S0956-7135(03)00009-4

[2] ICO (International Coffee Organization) (2015)

[3] Duarte, G.S. and Farah, A. (2011) Effect of Simultaneous Consumption of Milk and Coffee on Chlorogenic Acids' Bioavailablity in Humans. Journal of Agricultural and Food Chemistry, 59, 7925-7931. https://doi.org/10.1021/jf201906p

[4] Irish Coffee Council and Amárach Research (2016) What Your Coffee Says about 
You.

[5] Bücking, M. and Steinhart, H. (2002) Headspace GC and Sensory Analysis Characterization of the Influence of Different Milk Additives on the Flavour Release of Coffee Beverages. Journal of Agricultural and Food Chemistry, 50, 1529-1534. https://doi.org/10.1021/jf011117p

[6] Cristovam, E., Russell, C., Paterson, A. and Reid, E. (2000) Gender Preference in Hedonic Ratings for Espresso and Espresso Milk-Based Coffees. Food Quality and Preference, 11, 437-444. https://doi.org/10.1016/S0950-3293(00)00015-X

[7] Narain, C., Paterson, A., Piggott, J.R. and Dhawan, M. (2004) Whitening and Sweetening Influences on Filter Coffee Preference. British Food Journal, 106, 465-478. https://doi.org/10.1108/00070700410539770

[8] Stokes, C., O’Sullivan, M.G. and Kerry, J.P. (2016) Assessment of Black Coffee Temperature Profiles Consumed from Paper-Based Cups and Effect on Affective and Descriptive Product Sensory Attributes. International Journal of Food Science and Technology, 51, 2041-2048. https://doi.org/10.1111/ijfs.13176

[9] Stokes, C., O’Sullivan, M.G. and Kerry, J.P. (2017) Hedonic and Descriptive Sensory Evaluation for Development of Novel Instant and Fresh Coffee Products. European Food Research and Technology, 243, 331-340. https://doi.org/10.1007/s00217-016-2747-4

[10] Stokes, C., Kerry, J.P. and O’Sullivan, M.G. (2018) Rapid Descriptive Consumer Analysis Using Simultaneous and Monadic Sample Presentation for Coffee. Food and Nutrition Sciences, 9, Article ID: 82299. https://doi.org/10.4236/fns.2018.92005

[11] NCAUSA (National Coffee Association USA) (2016) How to Brew Coffee. http://www.ncausa.org/i4a/pages/index.cfm?pageID=71

[12] ISO (International Organization for Standardization) (2008) ISO 6668 Green Coffee-Preparation of Samples for Use in Sensory Analysis. ISO, Genève, Switzerland.

[13] Stone, H. and Sidel, J.L. (2004) 7-Affective Testing. In: Stone, H. and Sidel, J.L., Eds., Sensory Evaluation Practices. Food Science and Technology, International Series, 3rd Edition, Academic Press/Elsevier, USA, 247-277. https://doi.org/10.1016/B978-012672690-9/50011-1

[14] ISO (International Organization for Standardization) (2007) ISO 8589 Sensory Analysis: General Guidance for Design of Test Rooms. ISO, Genèva, Switzerland.

[15] MacFie, H.J., Bratchell, N., Greenhoff, K. and Vallis, L.V. (1989) Designs to Balance the Effect of Order of Presentation and First-Order Carry-Over Effects in Hall Tests. Journal of Sensory Studies, 4, 129-148. https://doi.org/10.1111/j.1745-459X.1989.tb00463.x

[16] Stone, H., Bleibaum, R. and Thomas, H. (2012) Test Strategy and Design of Experiments. In: Stone, H., Bleibaum, R.N. and Thomas, H.A., Eds., Sensory Evaluation Practices, 4th Edition, Elsevier Academic Press, Cambridge, 117-157.

[17] Richter, V., Almeida, T., Prudencio, S. and Benassi, M. (2010) Proposing a Ranking Descriptive Sensory Method. Food Quality and Preference, 21, 611-620. https://doi.org/10.1016/j.foodqual.2010.03.011

[18] Martens, H. and Martens, M. (2001) Multivariate Analysis of Quality: An Introduction. In: Measurement Science and Technology, 2nd Edition, Vol. 12, John Wiley \& Sons Ltd., New York, 445.

[19] O’Sullivan, M.G. (2017) Sensory Affective (Hedonic) Testing. In: A Handbook for Sensory and Consumer Driven New Product Development. Innovative Technologies for the Food and Beverage Industry, Woodhead Publishing Ltd., CH3, 39-57. 
https://doi.org/10.1016/B978-0-08-100352-7.00003-8

[20] O’Sullivan, M.G., Cruz-Romero, M. and Kerry, J.P. (2018) Affective and Descriptive (Novel) Sensory and Physiochemical Comparison of Traditional Bone-In Dry-Aged Beef Loin with Bone-Less Dry Ageing and Ageing Using a Moisture Permeable Bag. Food and Nutrition Sciences. https://doi.org/10.4236/fns.2018.99079

[21] O’Sullivan, M.G., Le Floch, S. and Kerry, J.P. (2015) Resting of MAP (Modified Atmosphere Packed) Beef Steaks Prior to Cooking and Effects on Consumer Quality. Meat Science, 101, 13-18. https://doi.org/10.1016/j.meatsci.2014.10.030

[22] O’Sullivan, M.G., Cruz, M. and Kerry, J.P. (2011) Evaluation of Carbon Dioxide Flavour Taint in Modified Atmosphere Packed Beef Steaks. LWT-Food Science and Technology, 44, 2193-2198. https://doi.org/10.1016/j.lwt.2011.06.010

[23] Conroy, P.M., O’Sullivan, M.G., Hamill, R.H. and Kerry, J.P. (2018) Impact on the Physicochemical and Sensory Properties of Salt- and Fat-Reduced Traditional Irish Breakfast Sausages on Various Age Cohorts Acceptance. Meat Science, 143, 190-198. https://doi.org/10.1016/j.meatsci.2018.04.037

[24] Tobin, B.D., O’Sullivan, M.G., Hamill, R.M. and Kerry, J.P. (2012) Effect of Varying Salt and Fat Levels on the Sensory Quality of Beef Patties. Meat Science, 4, 460-465. https://doi.org/10.1016/j.meatsci.2012.02.032

[25] Tobin, B.D., O’Sullivan, M.G., Hamill, R.M. and Kerry, J.P. (2012) Effect of Varying Salt and Fat Levels on the Sensory and Physiochemical Quality of Frankfurters. Meat Science, 92, 659-666. https://doi.org/10.1016/j.meatsci.2012.06.017

[26] Tobin, B.D., O'Sullivan, M.G., Hamill, R.M. and Kerry, J.P. (2013) The Impact of Salt and Fat Level Variation on the Physiochemical Properties and Sensory Quality of Pork Breakfast Sausages. Meat Science, 93, 145-152. https://doi.org/10.1016/j.meatsci.2012.08.008

[27] Tobin, B.D., O’Sullivan, M.G., Hamill, R.M. and Kerry, J.P. (2013) European Consumer Attitudes on the Associated Health Benefits of Neutraceutical-Containing Processed Meats Using Co-Enzyme Q10 as a Sample Functional Ingredient. Meat Science, 97, 207-213. https://doi.org/10.1016/j.meatsci.2014.01.010

[28] Tobin, B.D., O’Sullivan, M.G., Hamill, R.M. and Kerry, J.P. (2014) Effect of Cooking and in Vitro Digestion on Co-Enzyme Q10 in Processed Meat Products Fortified with Co-Enzyme Q10. Food Chemistry, 150, 187-192.

https://doi.org/10.1016/j.foodchem.2013.10.138

[29] O’Sullivan, M.G. (2017) Rapid Sensory Profiling Methods. In: A Handbook for Sensory and Consumer Driven New Product Development. Innovative Technologies for the Food and Beverage Industry, Woodhead Publishing Ltd., CH4, 59-82. https://doi.org/10.1016/B978-0-08-100352-7.00004-X

[30] Kilcawley, K.N., Faulkner, H., Clarke, H.J., O’Sullivan, M.G. and Kerry, J.P. (2018) Factors Influencing the Flavour of Bovine Milk and Cheese from Grass Based Versus Non-Grass Based Milk Production Systems. Foods, 7, 37. https://doi.org/10.3390/foods7030037

[31] Faulkner, H., O’Sullivan, M.G., Kerry, J.P. and Kilcawley, K.N. (2017) Impact of Different Forage Types on the Volatile and Sensory Properties of Bovine Milk. Journal of Dairy Science, 101, 1034-1047. https://doi.org/10.3168/jds.2017-13141

[32] Fellendorf, S., O'Sullivan, M.G. and Kerry, J.P. (2015) Impact of Varying Salt and Fat Levels on the Physiochemical Properties and Sensory Quality of White Pudding Sausages. Meat Science, 103, 75-82. https://doi.org/10.1016/j.meatsci.2014.12.010

[33] Fellendorf, S., O’Sullivan, M.G. and Kerry, J.P. (2017) Effect of Different Salt and 
Fat Levels on the Physicochemical Properties and Sensory Quality of Black Pudding. Food Science \& Nutrition, 5, 273-284. https://doi.org/10.1002/fsn3.390

[34] Fellendorf, S., O’Sullivan, M.G. and Kerry, J.P. (2016) Effect of Using Replacers on the Physicochemical Properties and Sensory Quality of Low Salt and Low Fat White Puddings. European Food Research and Technology, 242, 2105-2118. https://doi.org/10.1007/s00217-016-2707-z

[35] Fellendorf, S., O’Sullivan, M.G. and Kerry, J.P. (2016) Impact of Using Replacers on the Physicochemical Properties and Sensory Quality of Reduced Salt and Fat Black Pudding. Meat Science, 113, 17-25. https://doi.org/10.1016/j.meatsci.2015.11.006

[36] Fellendorf, S., Kerry, J.P., Hamill, R.H. and O'Sullivan, M.G. (2018) Impact on the Physicochemical and Sensory Properties of Salt Reduced Corned Beef Formulated with and without the Use of Salt Replacers. LWT-Food Science and Technology, 92, 584-592. https://doi.org/10.1016/j.lwt.2018.03.001

[37] Fellendorf, S., Kerry, J.P. and O’Sullivan, M.G. (2018) Consumer Attitudes on Salt and Fat Reduced Foods in the Republic of Ireland. Food and Nutrition Sciences, 9, 880-898. https://doi.org/10.4236/fns.2018.97066

[38] Hempel, A., O’Sullivan, M.G., Papkovsky, D. and Kerry, J.P. (2013) Use of Optical Oxygen Sensors to Monitor Residual Oxygen in Pre- and Post-Pasteurised Bottled Beer and Its Effect on Sensory Attributes and Product Acceptability during Simulated Commercial Storage. LWT-Food Science and Technology, 50, 226-231. https://doi.org/10.1016/j.lwt.2012.05.026

[39] Hempel, A., O’Sullivan, M.G., Papkovsky, D. and Kerry, J.P. (2013) Non-Destructive and Continuous Monitoring of Oxygen Levels in Modified Atmosphere Packaged Ready-to-Eat Mixed Salad Products Using Optical Oxygen Sensors. Journal of Food Science, 78, S1057-S1062. https://doi.org/10.1111/1750-3841.12164

[40] Hempel, A., O’Sullivan, M.G., Papkovsky, D. and Kerry, J.P. (2013) Assessment and Use of Optical Oxygen Sensors as Tools to Assist in Optimal Product Component Selection for the Development of Packs of Ready-to-Eat Mixed Salads and for the Non-Destructive Monitoring of In-Pack Oxygen Levels Using Chilled Storage. Foods, 2, 213-224. https://doi.org/10.3390/foods2020213

[41] Hempel, A., O’Sullivan, M.G., Papkovsky, D. and Kerry, J.P. (2013) Use of Smart Packaging Technologies for Monitoring and Extending the Shelf-Life Quality of Modified Atmosphere Packaged (MAP) Bread: Application of Intelligent Oxygen Sensors and Active Ethanol Emitters. European Food Research and Technology, 237, 117-124. https://doi.org/10.1007/s00217-013-1968-Z

[42] Richardson, A.M., Tyuftin, A., Kilcawley, K.N., Gallagher, E., O’Sullivan, M.G. and Kerry, J.P. (2018) Impact of Sugar Particle Size Manipulation on the Physical and Sensory Properties of Chocolate Brownies. LWT-Food Science and Technology, 95, 51-57. https://doi.org/10.1016/j.lwt.2018.04.038

[43] Bertuzzi, A.S., Kilcawley, K.N., Sheehan, J.J., O’Sullivan, M.G., Kennedy, D., McSweeney, P.L.H. and Rea, M.C. (2017) Use of Smear Bacteria and Yeasts to Modify Flavour and Appearance of Cheddar Cheese. International Dairy Journal, 72, 44-54. https://doi.org/10.1016/j.idairyj.2017.04.001

[44] Cavanagh, D., Kilcawley, K.N., O’Sullivan, M.G., Fitzgerald, G.F. and McAuliffe, O. (2014) Assessment of Wild Non-Dairy Lactococcal Strains for Flavour Diversification in a Mini Gouda Type Cheese Model. Food Research International, 62, 432-440. https://doi.org/10.1016/j.foodres.2014.03.043

[45] Delgado-Pando, G., Allen, P., Fischer, E., O’Sullivan, M.G., Kerry, J.P. and Hamill, R.M. (2018) Salt Content and Minimum Acceptable Levels in Whole-Muscle Cured 
Meat Products. Meat Science, 139, 179-186.

https://doi.org/10.1016/j.meatsci.2018.01.025

[46] Guerrero, P., O’Sullivan, M.G., Kerry, J.P. and de la Caba, K. (2015) Application of Soy Protein Coatings and Their Effect on the Quality and Shelf-Life Stability of Beef Patties. Royal Society of Chemistry Advances, 5, 8182-8189. https://doi.org/10.1039/C4RA13421D

[47] Henneberry, S., O’Sullivan, M.G., Kilcawley, K.N., Kelly, P.M., Wilkinson, M.G. and Guinee, T.P. (2016) Sensory Quality of Unheated and Heated Mozzarella-Style Cheeses with Different Fat, Salt and Calcium Levels. International Journal of Dairy Science, 69, 38-50. https://doi.org/10.1111/1471-0307.12300

[48] Hickey, C.D., O’Sullivan, M.G., Davis, J., Scholz, D., Kilcawley, K.N., Wilkinson, M.G. and Sheehan, J.J. (2018) The Effect of Buttermilk or Buttermilk Powder Addition on Functionality, Textural, Sensory and Volatile Characteristics of Cheddar-Style Cheese. Food Research International, 103, 468-477. https://doi.org/10.1016/j.foodres.2017.09.081

[49] O’Callaghan, T., Mannion, D.T., Hennessy, D., McAuliffe, S., O’Sullivan, M.G., Leeuwebdaal, N., Beresford, T.P., Dillon, P., Kilcawley, K.N., Sheehan, D.J., Ross, P. and Stanton, C. (2017) Effect of Pasture versus Indoor Feeding Systems on Quality Characteristics, Nutritional Composition, and Sensory and Volatile Properties of Full-Fat Cheddar Cheese. Journal of Dairy Science, 100, 6053-6073.

https://doi.org/10.3168/jds.2016-12508

[50] O’Callaghan, T., Faulkner, H., McAuliffe, S., O’Sullivan, M.G., Hennessy, D., Dillon, P., Kilcawley, K.N., Stanton, C. and Ross, P. (2016) Quality Characteristics, Chemical Composition, and Sensory Properties of Butter from Cows on Pasture versus Indoor Feeding Systems. Journal of Dairy Science, 99, 9441-9460.

https://doi.org/10.3168/jds.2016-11271

[51] Rodríguez-Calleja, J.M., Cruz-Romero, M.C, O’Sullivan, M.G. and Kerry, J.P. (2012) High-Pressure-Based Hurdle Strategy to Extend the Shelf-Life of Fresh Chicken Breast Fillets. Food Control, 25, 516-524. https://doi.org/10.1016/j.foodcont.2011.11.014

[52] Stefanovic, E., Kilcawley, K.N., Roces, C., Rea, M., O’Sullivan, M.G., Sheehan, J.J. and McAuliffe, O. (2018) Evaluation of the Potential of Lactobacillus paracasei Adjuncts for Flavor Compounds Development and Diversification in Short-Aged Cheddar Cheese. Frontiers in Microbiology, 9, 1506.

https://doi.org/10.3389/fmicb.2018.01506

[53] Walsh, A., Crispie, F., Kilcawley, K.N., O’Sullivan, O., O’Sullivan, M.G., Claesson, M. and Cotter, P. (2016) Microbial Succession and Flavour Production in the Fermented Dairy Beverage Kefir. mSystems, No. 5, e00052-16.

https://doi.org/10.1128/mSystems.00052-16

[54] Yarlagadda, A., Wilkinson, M.G., Ryan, S., Doolan, A.I., O’Sullivan, M.G. and Kilcawley, K.N. (2014) Utilisation of a Cell Free Extract of Lactic Acid Bacteria Entrapped in Yeast to Enhance Flavour Development in Cheddar Cheese. International Journal of Dairy Science Technology, 67, 21-30. https://doi.org/10.1111/1471-0307.12099

[55] Yarlagadda, A., Wilkinson, O’Sullivan, M.G. and Kilcawley, K.N. (2014) Utilisation of Microfluidisation to Enhance Enzymatic and Metabolic Potential of Lactococcal Strains as Adjuncts in Gouda Type Cheese. International Dairy Journal, 38, 124-132. https://doi.org/10.1016/j.idairyj.2014.01.007 
[56] Chiralertpong, A., Terry, E. and Barnard, J. (2008) Tatse-Odor Integration in Espresso Coffee. Chemical Perception, 1, 147-152.

[57] Narain, C., Paterson, A. and Reid, E. (2003) Free Choice and Conventional Profiling of Sensory Character in Whitened and Sweetened Commercial Filter Coffees. Food Quality and Preference.

[58] Lundgren, B., Jonsson, B., Pangborn, R.M., Sontag, A.M., Barylko-Pikielna, N., Pietrzak, E., Garruti, R.D.S., Moraes, M.A.C. and Yoshida, M. (1978) Taste Discrimination vs. Hedonic Response to Sucrose in Coffee Beverage. An Interlaboratory Study. Chemical Senses, 3, 249-265. https://doi.org/10.1093/chemse/3.3.249

[59] ICO (International Coffee Organization) (2002) Assessor Orientated Vocabulary for Coffee. http://www.ico.org 